College, London, estimated that roundabouts reduce accidents by 60 per cent. R. L. Moore of the Road Research Laboratory emphasized that "police, magistrates, road engineers and road users in general should not assume that because visibility is good in the sense that there are no physical obstructions, a driver can, or should, be able to see everything. . . . When at some point in the road system drivers fail consistently, the system needs examination rather than the driver".

Motorway travel has proved to be the safest in England, with only 0.7 accidents per million vehicle miles compared with $1 \cdot 6$ accidents per million vehicle miles on rural dual carriageways or $2 \cdot 1$ on rural threelane carriageways, but there have been several multiple crashes, usually during periods of decreased visibility. Since most motorists expect free flow on a motorway, they are not at their most alert and are not prepared for obstructions. To deal with this problem, more comprehensive signalling is being installed, the first on the Severn Bridge section of the M4. A similar experiment on the John Lodge Freeway in the United States is supposed to have reduced journey times by 5 to 25 per cent.

\section{Saving York Minster}

Display boards showing the progress of an appeal for restoration funds are a familiar sight outside churches throughout Britain. The largest appeal of this kind was launchod just over a year ago by York Minster,

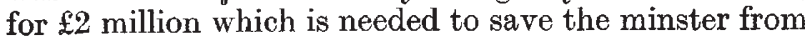
collapse. About three-quarters of this amount has already been raised. The fabric of York Minster has long becn under superficial repair to renew decayed stonework-the scaffolding which for years enclosed the west end is evidence of this-but the discovery

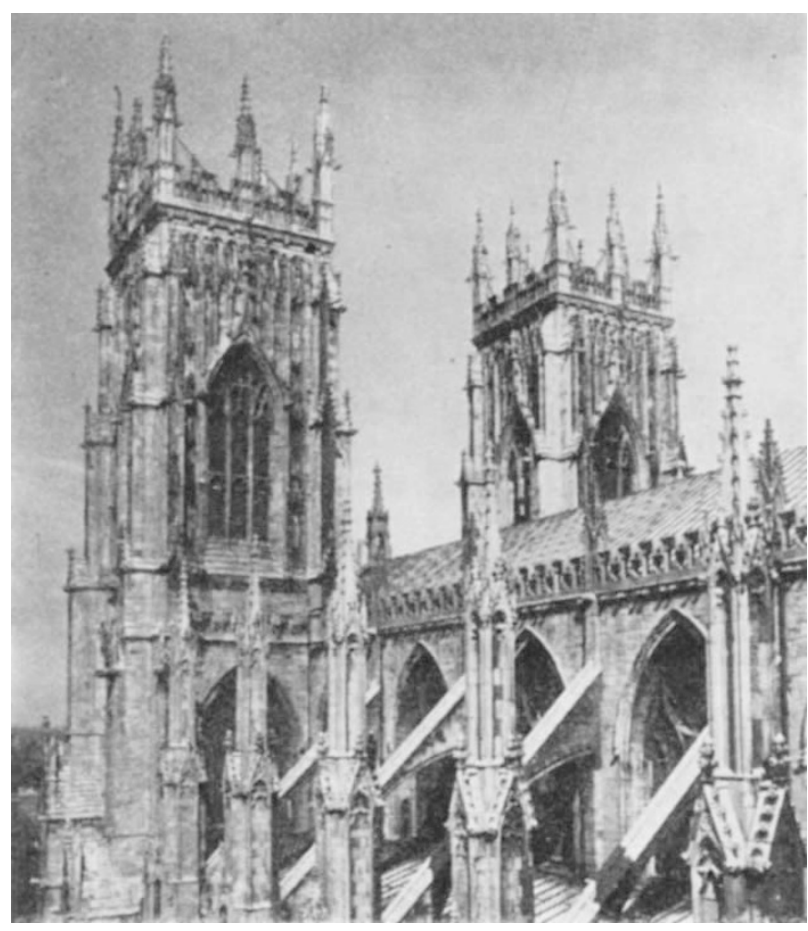

York Minster-some of the roof and facing which is in urgent need of repair. that the building was actually in danger of collapse was made quite recently. A thorough survey of the minster was carried out in 1965 and 1966 , when ominous cracks were found in the piers supporting the massive central tower, and in part of the choir. On the pretext of an archaeological dig, an excavation to the foundations of the tower was made to look for the cause of the trouble. The problem seems to be that the twelfth century foundations of the minster are just not strong enough to support the weight of the tower, added early in the fifteenth century. The foundations of the tower itself are four massive piers which have to stand up to stresses reaching $\mathbf{4 6}$ tons per square foot-more than three times the maximum permitted by current building codes and greater than the crushing strength of the

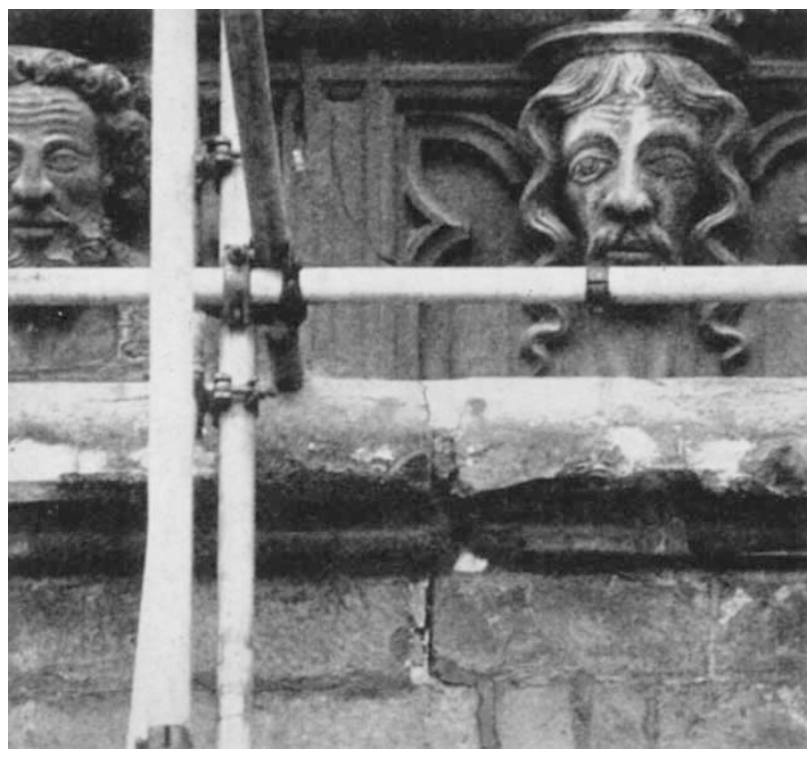

A crack which threatens the great east window.

mortar binding the blocks together. It is hardly surprising that the foundations are bulging under the pressure from above.

'Ihis comparatively recent deterioration in the condition of the minster is likely to have its origin in the improvement in the drainage in the York area over the past century. Since the last examination of the foundations in 1837, the water table in the glacial material on which the minster rests has sunk by $4 \mathrm{ft}$. This means that the foundations, which used to be supported to some extent by waterlogged soil, are now free to bulge under the excessive pressure. Work is now going on to strengthen the foundations of the central tower by the insertion of steel struts between the four piers, and the construction of concrete rafts to spread the weight of the tower over a larger area.

To arrest the deterioration of the superstructure of the tower, it is to be surrounded by a steel girdle at the level of the roof of the nave and a reinforced concrete ring beam is to be fitted at the top. The tendency for the tower to collapse has caused the east wall of the minster, which includes a Perpendicular window containing some magnificent stained glass, to lean outwards by up to about two feet. To save this part of the minster, massive steel shoring is being erected.

It is clearly going to be several years yet before the 
work at York is completed and the largest mediaeval cathedral in Britain is saved from the danger of collapse. The appeal fund of $£ 2$ million, based on what was necessarily only an approximate estimate of the restoration, is planned to be spent by 1975 . With luck, this amount will cover the work, but in 1967 estimates of the cost ranged up to $£ 2.6$ million. The obvious answer-that the Church Commissioners support the appeal-seems to be out of the question. Although the Church Commissioners make grants towards the pay of the clergy and lay staff, they are forbidden by statute to contribute to the maintenance of the building itself.

\section{Sheffield Honours Chapman}

Professor Sydney Chapman, the geophysicist, is 80 this year, and to mark the occasion Sheffield University last week awarded him the honorary degree of Doctor of Science. To add to the celebrations, the university held a three day conference attended by Professor Chapman, by many of his friends and by more than 100 space scientists. The theme of the conference was the solar-terrestrial environment, and the eight topics covered were chosen to reflect Professor Chapman's interests over the years. Study of interactions between the Sun and the Earth has during the past few years developed into a major

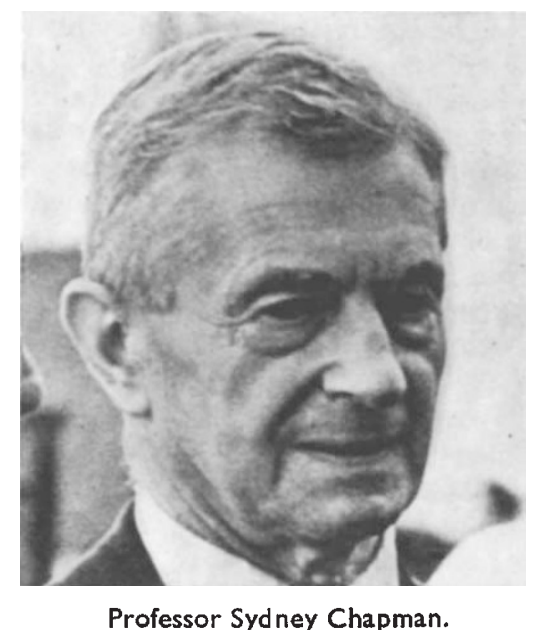

field of research, chiefly because of the way the upper atmosphere can now be investigated by rockets and satellites, but the inception of the subject owes as much to Professor Chapman as to anyone. Nevertheless, the conference was rarely retrospective, and the papers presented gave an insight into the research which is now being carried out.

The work going on in the space sciences at the University of Sheffield was, of course, well represented. This is chiefly concerned with the theory of the ionosphere, radar observations of meteors and ionosphere and very low frequency investigations from rockets and satellites. Some of the results reported by the Sheffield groups were of very low frequency radio noise measured by the Sheffield experiment on Ariel 3.

Not all the papers read at Sheffield described positive results, however. J. F. Kerridge of Birkbeck College, who summarized the recent rocket and satellite attempts to collect samples of interplanetary dust, said the experiments had been thwarted by contamination problems. This means that the notion that the Earth is surrounded by a substantial dust cloudwhich seemed quite likely a few years ago-is in fact not the case. At lower levels, Dr D. W. Parkin has for some years now carried out searches for particles of interplanetary dust which may have drifted down in the atmosphere. Dr Parkin said at Sheffield that the metal fragments and black magnetic spherules collected from nylon meshes exposed to the wind at a site in Barbados, and earlier described as extra-terrestrial, are contaminants introduced by handling. This lack of information on the rate of influx of minute particles of interplanetary dust is just now one of the uncertainties in estimates of the accretion of extraterrestrial material by the Earth.

\section{Feeding before Birth}

Nutrition of the foetus and the newly born was the theme of the 202nd meeting of the Nutrition Society held on July 12-13 at the School of Anatomy, Cambridge University. The meeting was well attended, and the papers were followed by constructive discussion, but the overall impression was that much remains to be done.

On the first day - with Dr E. Kodicek, director of the Dunn Nutritional Laboratory as chairman-Dr Elsie M. Widdowson set the pace with a talk on the way the foetus is fed. She discussed the passage of various substances such as potassium, sodium, phosphorus and calcium across the placenta, and added that active transfer has been invoked as a likely mechanism, especially in view of the fact that potassium, calcium and phosphorus attain a higher concentration in foetal plasma than in maternal plasma. Although the gradients across various parts of the placenta are not fully understood, it does seem that the placenta can alter certain substances during their passage through to the foetus.

This was followed by a physiological basis for assessing protein requirements during pregnancy, put forward by Dr D. J. Naismith, who referred to the parasitic relationship of the foetus to the mother. $\mathrm{He}$ proposed a scheme for the endocrine control of protein metabolism of the maternal organism which ensures a continuous supply of amino-acids for synthesis of foetal protein; the adrenal corticosteroids and oestrogens seem to be particularly concerned.

During the afternoon Dr Heather J. Shelley and Dr G. A. Neligan talked about carbohydrate metabolism in the foetus and the newly born, and hypoglycaemia in the newly born baby. According to Dr Shelley, glucose of maternal origin passes freely across the placenta and is both the main metabolic fuel in the foetus and the principal substrate for fat and glycogen synthesis. Most species, including man, accumulate glycogen in the liver and skeletal muscles during the last part of gestation and these stores are utilized immediately after birth. The ability to degrade aminoacids and synthesize glucose from three-carbon compounds does not develop until after birth, but the activity of the enzymes involved rises above that of the adult during the suckling period. The rapid utilization of liver glycogen after birth and the small capacity for gluconeogenesis at birth is probably responsible for 